\title{
Experimental studies of charge density distribution in the crystals of cytisine and N-methylcytisine. Inside the Fake Tobacco
}

\author{
Agata Owczarzak $^{1}$ • Anita M. Grześkiewicz ${ }^{1} \cdot$ Maciej Kubicki $^{1}$ (D)
}

Received: 31 March 2017 / Accepted: 16 May 2017 /Published online: 8 June 2017

(C) The Author(s) 2017. This article is an open access publication

\begin{abstract}
The high-resolution X-ray data for two bioactive molecules: cytisine (1) and its N-methyl derivative (2) have been collected up to $\sin \theta / \lambda=1.12 \AA^{-1}$ for $\mathbf{1}$ and $1.0 \AA^{-1}$ for $\mathbf{2}$. This data was used for modeling of the fine features of electron density distribution, including bonding density and electron lone pairs. The quality of the model was checked by, e.g., rigid bond test and RDA analysis. The topological analysis (gradient field analysis) has been also performed for both inter- and intramolecular interactions. In case of $\mathbf{1}$ a number of intermolecular interactions, from relatively strong $\mathrm{N}-\mathrm{H} \cdots \mathrm{O}$ hydrogen bonds to weak $\mathrm{H} \cdots \mathrm{H}$ contacts was found, and their topological features were analyzed. For N-methyl derivative, only few intermolecular bonding contacts were found. The analyzed features show that besides the structural similarities of both alkaloids, the electron density distribution and consequently all its derivatives differ quite significantly in places.
\end{abstract}

Keywords Cytisine - NACh receptor · Electron density · Hansen-Coppens model · Topological analysis · AIM theory

This paper is dedicated to Professor Lou Massa on the occasion of his Festschrift: A Path through Quantum Crystallography

Electronic supplementary material The online version of this article (doi:10.1007/s11224-017-0972-5) contains supplementary material, which is available to authorized users.

Maciej Kubicki

mkubicki@amu.edu.pl

1 Department of Chemistry, Adam Mickiewicz University, Umultowska89, 61-614 Poznań, Poland

\section{Introduction}

Cytisine is a quinolizidine alkaloid obtained from plants belonging to the Fabaceae (Leguminosae) family. For centuries, it has been used in traditional medicine in the treatment of, e.g., migraine, insomnia, asthma, or cough. More recently, it has gained more popularity due to its pharmacological action closely resembling that of nicotine [1-3]. During the Second World War, leaves of Cytisus Laburnum (known also as "golden chain" or "golden rain") were used as a tobacco substitute, and Russian soldiers referred to the plant as "fake tobacco" $[2,4]$.

Nicotinic receptors form a family of acetylcholine (Ach)gated cation channels made up of different subtypes, localized in the central and peripheral nervous systems $[5,6]$. Nicotine, a naturally occurring alkaloid, affects the functioning of peripheral nervous system. It stimulates secretion of catecholamines, leading to increased blood pressure and sugar concentration, which alleviates nicotine withdrawal symptoms and stimulation of the respiratory system $[2,7]$. Comparison of the structures of nicotine and cytisine (Scheme 1) showed that the quasi-aromatic ring in cytisine and the pyridine ring in nicotine are associated in a similar way with respect to the nitrogen atom in the bispidine ring system (cytisine) and in the pyrrolidine ring (nicotine) [8]. Cytisine shows an affinity towards the specific subunits of nicotine acetylcholine receptors, nAChRs. It acts as a partial agonist at the $\alpha 4 \beta 2$ subunit, and very potently binds to the $\alpha 3 \beta 4, \alpha 7$ nicotinic subunits [5]. So, cytisine possesses a structure and mechanism of action that are similar to those of nicotine, but it has much lower toxicity $[9,10]$. Therefore, cytisine has been applied in nicotine replacement therapy in the form of Tabex $\AA$, Desmoxan $®$, Chantix ${ }^{\circledR}$ etc. 
Scheme 1 Comparison of the structures of nicotine and cytisine<smiles>O=c1cccc2n1CC1CNCC2C1</smiles>

Cytisine<smiles>CN1CC2CC(C1)c1cccc(=O)n1C2</smiles>

$\mathrm{N}$-methylcytisine<smiles>CN1CCCC1c1cccnc1</smiles>

Nicotine
Current research focuses on the search of novel compounds - potential therapeutics which are more lipophilic, therefore having improved ability to pass the blood-brain barrier, but still retain the high affinity for $\alpha 4 \beta 2$ subtype receptors $[2,9]$. Moreover, cytisine derivatives have been explored as potential drugs against Alzheimer's and Parkinson's, attention deficit, hyperactivity disorder diseases [9-11].

High-resolution X-ray crystallography can be used as a main tool in the analysis of the structure-activity relationships. Here, we present the analysis of a charge density distribution and intermolecular interactions in the cytisine $[(-)-1,2,3,4,5,6-$ Hexahydro-1,5-methano-8H-pyrido $(1,2-\mathrm{a})(1,5)$ diazocin-8one] (1) and N-methylcytisine [(-)-1,2,3,4,5,6-hexahydro-3methyl-1,5-methano-8H-pyrido(1,2-a)(1,5)diazocin-8-one] (2) crystals. The results of these studies are supposed to provide high-quality electron density distribution data, which can be used not only in SAR studies but also in docking studies of the active site if the appropriate receptor.

Those two compounds, despite the relatively small changes in their structures, display quite significant differences in affinity towards $\alpha 4 \beta 2$ subtype of AChRs [12]. It has been hypothesized that much lower affinity of N-methylcytisine is probably due to the steric hindrance with Tyr-91 [12] or to lack of the possibility of forming hydrogen bonds with hydroxyl group of Tyr-91 or backbone carbonyl of Trp-145, which is formed in case of cysteine.

\section{Experimental}

\section{X-ray data}

Crystal data and refinement details are presented in Table 1. High-resolution X-ray diffraction data were collected at 100(1)K (under nitrogen flow $5 \mathrm{~L} / \mathrm{min}$ ), on an Oxford Diffraction Supernova Dual diffractometer, equipped with Atlas detector, and microfocus Mova tube with $\mathrm{MoK} \alpha$ radiation $(\lambda=0.71073 \AA)$. The temperature was controlled with an Oxford Instruments Cryosystem device. The data were corrected for Lorentz-polarization effects as well as for absorption (multiscan) [13]. Accurate unit-cell parameters were determined by a least-squares fit of 53,660 (1), and 47,045 (2) reflections of highest intensity, chosen from the whole experiment.

\section{IAM model refinement}

The calculations were mainly performed within the WinGX [14] and OLEX [15] program systems. The structures were solved with ShelxT [16] and refined (within the Independent Atom Model approximation) with the full-matrix leastsquares procedure on $\mathrm{F}^{2}$ by SHELXL97 [16]. Scattering factors incorporated in SHELXL97 were used. All non-hydrogen atoms were refined anisotropically, hydrogen atoms were located by difference Fourier synthesis, and isotropically refined.

Table 1 Crystallographic measurement and refinement data

\begin{tabular}{|c|c|c|}
\hline & Cytisine & N-methylcytisine \\
\hline Empirical formula & $\mathrm{C}_{11} \mathrm{H}_{14} \mathrm{~N}_{2} \mathrm{O}$ & $\mathrm{C}_{12} \mathrm{H}_{16} \mathrm{~N}_{2} \mathrm{O}$ \\
\hline Formula weight & 190.24 & 204.27 \\
\hline Crystal system & Orthorhombic & Orthorhombic \\
\hline Space group & $\mathrm{P} 2{ }_{1} 2_{1} 2_{1}$ & $\mathrm{P} 2{ }_{1} 2_{1} 2_{1}$ \\
\hline Temperature $[\mathrm{K}]$ & $100(1)$ & $100(1)$ \\
\hline a & $7.1358(1)$ & $8.9522(2)$ \\
\hline $\mathrm{b}$ & $9.8721(1)$ & $10.6757(2)$ \\
\hline $\mathrm{c}$ & $26.3831(3)$ & $11.1453(2)$ \\
\hline Volume & $1858.57(4)$ & $1065.17(4)$ \\
\hline $\mathrm{Mu}\left[\mathrm{mm}^{-1}\right]$ & 0.089 & 0.082 \\
\hline $\mathrm{Z}$ & 8 & 4 \\
\hline Resolution range $\left[\AA^{-1}\right]$ & $0.054-1.112$ & $0.086-1.003$ \\
\hline Reflections no. & 177,704 & 141,427 \\
\hline Unique reflections $\left(R_{\text {int }}\right)$ & $21,393(0.058)$ & $8954(0.022)$ \\
\hline \multicolumn{3}{|l|}{ IAM refinement } \\
\hline No .of parameters & 365 & 200 \\
\hline$R_{1}[I>2 \sigma(\mathrm{I}])$ & 0.0355 & 0.0361 \\
\hline $\mathrm{wR}_{2}[I>2 \sigma(\mathrm{I}])$ & 0.0952 & 0.1030 \\
\hline S & 1.15 & 1.04 \\
\hline Residual electron density $\left[\mathrm{e} \AA^{-3}\right.$ ] & $-0.31 / 0.60$ & $-0.52 / 0.69$ \\
\hline \multicolumn{3}{|l|}{ Multipolar refinement } \\
\hline No. of parameters & 905 & 518 \\
\hline$R_{1}[I>2 \sigma(\mathrm{I}])$ & 0.0252 & 0.0239 \\
\hline $\mathrm{wR}_{2}[I>2 \sigma(\mathrm{I}])$ & 0.0529 & 0.0529 \\
\hline S & 1.069 & 1.145 \\
\hline Residual electron density [e $\AA^{-3}$ ] & $-0.24 / 0.25$ & $-0.20 / 0.23$ \\
\hline
\end{tabular}




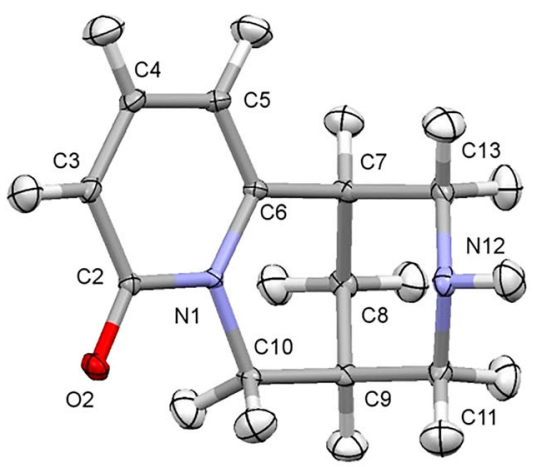

Cytisine molecule 1

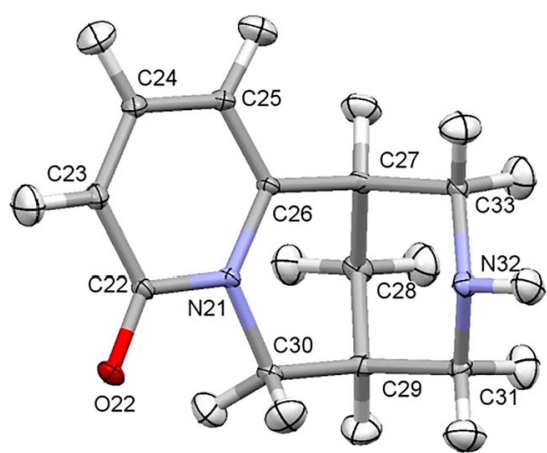

Cytisine molecule 2

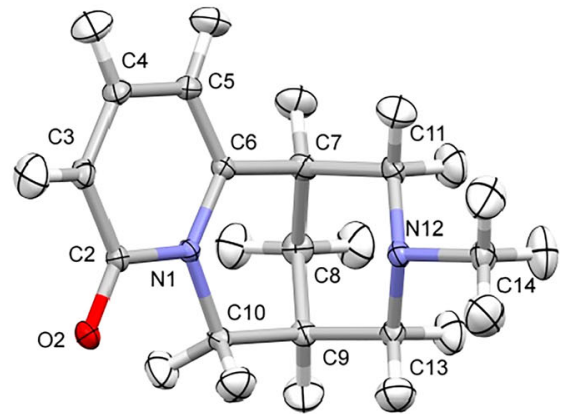

$\mathrm{N}$-methylcytisine

Fig. 1 Perspective views of (1) and (2) with the numbering schemes, ellipsoids are drawn at the 50\% probability level, anisotropic thermal parameters for hydrogen atoms were calculated with SHADE server [21]

\section{Multipolar refinement}

The charge density was subsequently refined against structure factor amplitudes with the MoPro suite [17] using the multipolar Hansen-Coppens model [18] for pseudoatom electron density:

$$
\begin{aligned}
\rho_{\text {atom }}(r) & =\rho_{\text {core }}(r)+P_{\text {val }} \kappa^{3} \rho_{\text {val }}(\kappa r) \\
& +\Sigma_{1} \kappa^{\prime 3} R_{1}\left(\kappa^{\prime} r\right) \Sigma_{\mathrm{m}} P_{\operatorname{lm} \pm} d_{\mathrm{lm} \pm}(\vartheta, \varphi)
\end{aligned}
$$

where the first two terms are the spherically averaged core and valence electron densities of the atom, and the last term corresponds to the non-spherical valence density which is described in terms of real spherical harmonic functions. $P_{\text {val }}$ is the valence population, $P_{1 \mathrm{~m} \pm}$ are the multipole populations and $\kappa$ and $\kappa$ ' are the contraction/expansion parameters. $R_{1}$ are radial Slater type functions:

$R_{l}(r)=\frac{\xi_{l}^{n l+3}}{\left(n_{l}+2\right) !} r^{n l} e^{-\xi_{l} r}$

The oxygen, carbon, and nitrogen atoms were refined up to octupolar level $\left(l_{\max }=3\right.$ and the hydrogen atoms up to dipole level $\left(l_{\max }=1\right)$. The $n_{1}$ and $\xi_{1}$ values were set equal to $2,2,2,3$, and $4.466 \mathrm{au}^{-1}(\mathrm{O}), 2,2,2,3$, and $3.176 \mathrm{au}^{-1}(\mathrm{C}), 2,2,2,3$, and $3.839 \mathrm{au}^{-1}(\mathrm{~N})$, and 1,1 , and $2.00 \mathrm{au}^{-1}(\mathrm{H})$. The core and valence scattering factors were calculated from Clementi and Roetti wave functions [19]. The structures have been refined against intensities, using several different strategies to obtain

\section{N-METHYLCYTISINE}

b)

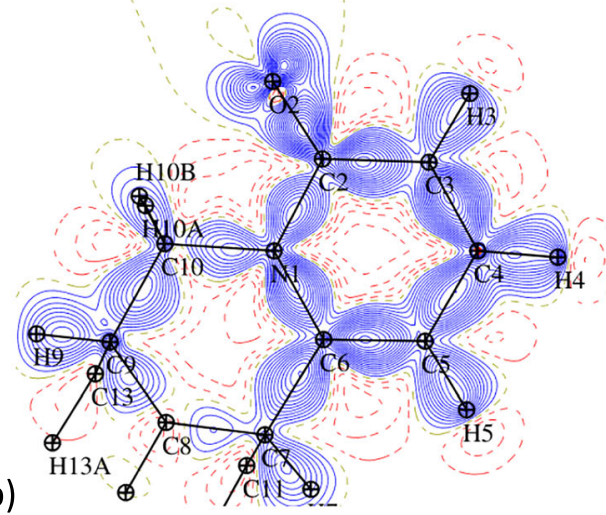

e)

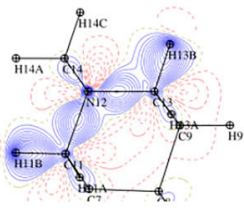

f)

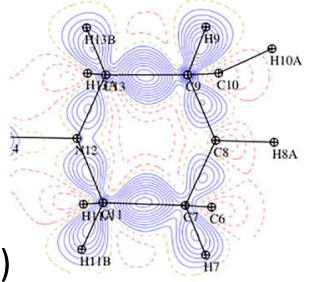

Fig. 2 The static deformation electron density distribution in plane of a, b pyridine ring $\mathbf{c}$, e N12-C11-C13 plane d, f, C9-C22-C7-C23 plane, the positive (blue) and negative (dashed red) contours are drawn at intervals $0.05 \mathrm{e} \AA^{-3}$ 
Fig. 3 The bond critical points in molecule 1 of $\mathbf{1}$ (left) and in $\mathbf{2}$ (right)
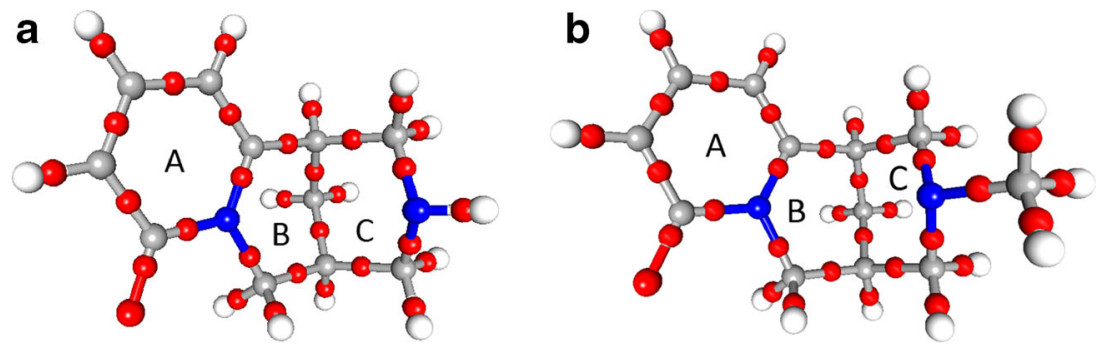

the best available model of crystal structures. The refinement was performed for $\sin \theta / \lambda$ up to $1.12 \AA^{-1}$ for cytisine (1) and to $1.0 \AA^{-1}$ for N-methylcytisine (2). Final refinement strategies for both compounds were similar. Initially, only the scale factor was refined, followed by non-hydrogen, the atomic positions and atomic displacement parameters (ADPs) against all reflections. Subsequently, a high-order $\left(\sin \theta / \lambda>0.7 \AA^{-1}\right)$ refinement for non-H atoms was performed, aiming at the deconvolution of the ADP's and bonding deformation effects [20]. The ADPs for $\mathrm{H}$ atoms were estimated using SHADE server [21]. X-H distances were constrained to average values obtained from the neutron diffraction studies. Then $P_{\text {val }}, \kappa$, $P_{\operatorname{lm}}$ and $\kappa$ ' were consecutively refined until convergence. The $\kappa$ an $\kappa$ ' values for $\mathrm{H}$ atoms were restrained to 1.13
(0.02) and 1.29 (0.02), respectively. Chemical equivalent atoms in two symmetry-independent molecules of $\mathbf{1}$ were restrained to be similar. The details of the data collection and crystallography statistics are summarized in Table 1.

The RDA (residual density analysis) [22] was performed for the final models. This kind of analysis, based on the fractal dimension of the residual electron density map, is used as a method of detection of the systematical errors and quantitative description of the deficiencies of the model. These problems are generally reflected in asymmetric shape of the appropriate plot. Fig. 1 Sup (cf. Supplementary material) shows that in case of both $\mathbf{1}$ and 2 the plots are quite symmetrical and regular which testifies for the quality of the final models.
Fig. 4 Graphical representation of Laplacian $\left[\nabla^{2}\left(\rho_{\mathrm{bcp}}\right)\left(\mathrm{e} \AA^{-5}\right)\right]$ electron density $\left[\rho_{\mathrm{bcp}}\left(\mathrm{e} \AA^{-3}\right)\right]$ and positive curvature of the Hessian matrix $\lambda_{3}$ in bond critical points for bonds not involving hydrogen atoms
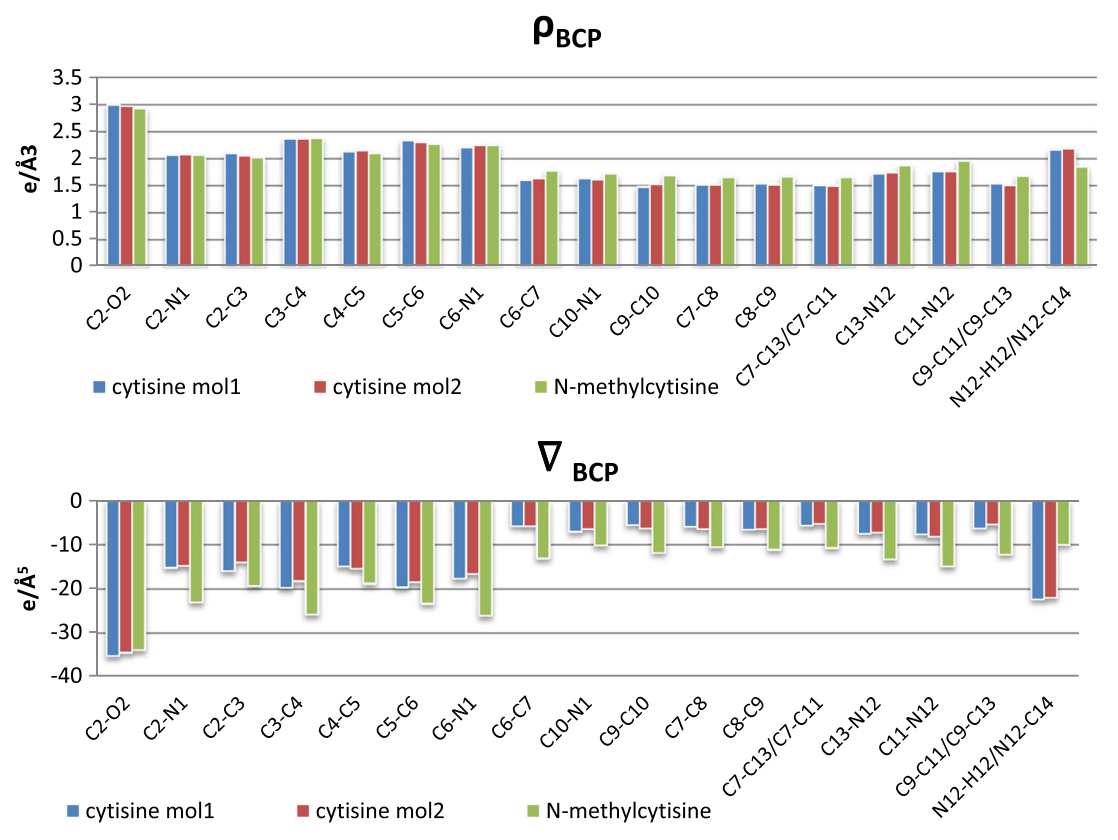

$\lambda_{3 \text { ВСР }}$

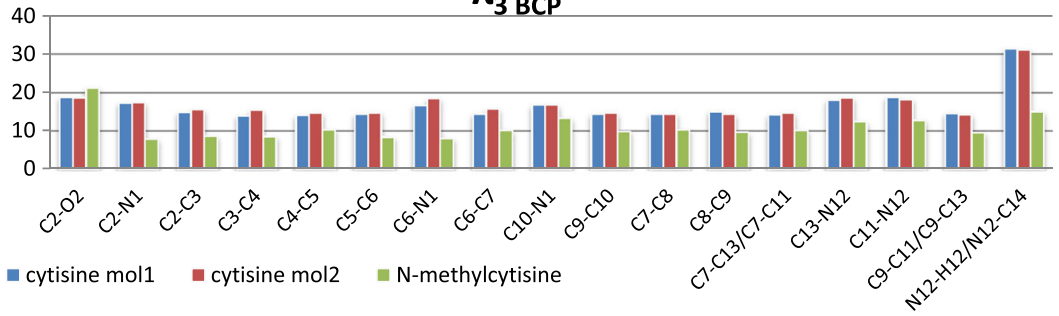




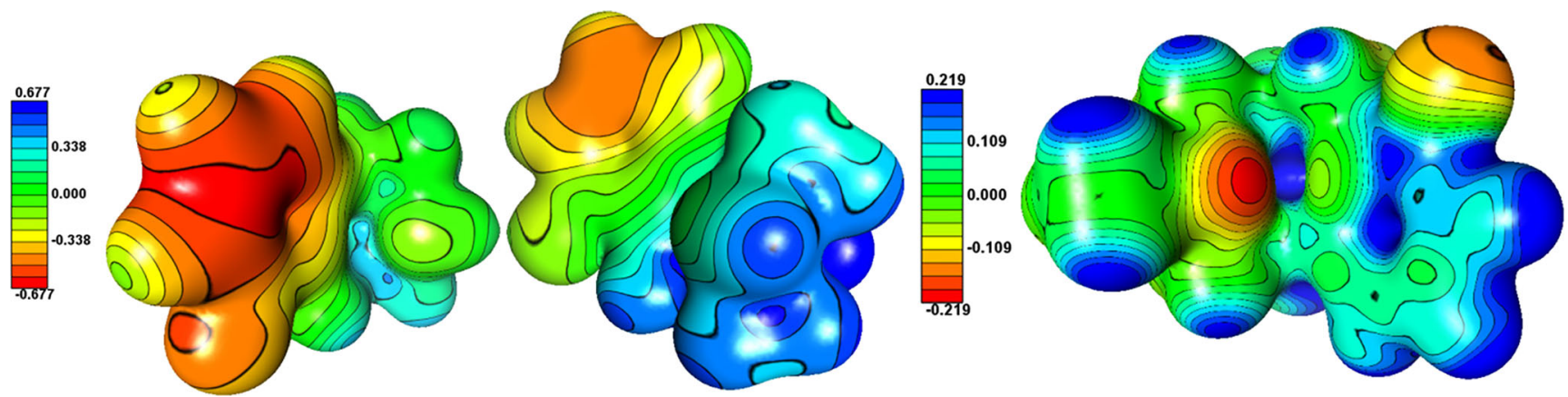

Fig. 5 Electrostatic potential mapped over same electron density iso-surface for cytisine molecules (left), and N-methylcytisine molecule (right). The iso-surfaces are drawn at $0.1 \mathrm{e} / \AA^{3}$

\section{Results and discussion}

The standard resolution, room temperature crystal structures of cytisine (1) and N-methylcytisine (2) have been reported earlier $[8,23,24]$. Both alkaloids crystallize in noncentrosymmetric space group P $22_{1} 2_{1}$. The asymmetric part of the unit cell contains two (almost identical) molecules in case of (-)-cytysine (1) and one for (-)-N-methylcytisine (2). The perspective views of the molecules are presented in Fig. 1. No phase transitions have been observed while lowering temperature down to $100 \mathrm{~K}$.

\section{Molecular geometries}

The Hirshfeld rigid bond test [20] was applied to the nonhydrogen atoms joined by the covalent bonds after the final multipolar refinement. For each pair of non-hydrogen atoms, the values of $\Delta \mathrm{Z}_{\mathrm{AB}}{ }^{2}$ (differences between the components of the $U_{\mathrm{ij}}$ tensor along the bond) do not exceed the acceptable value of $10^{-3} \AA^{2}$. The largest differences have been found for N1-C10/N21-C30 $(0.00066 / 0.00076)$ in 1 and for N1-C6
$(0.00091)$ in $\mathbf{2}$. The static deformation density maps, presented in Fig. 2, show expected bonding features: accumulation of electron density in the bonds in pyridine ring more significant than in piperidine one, electron lone pairs on oxygen atoms, and subtle change of electron density distribution in the vicinity of the structure modification - in this case, methylation on N12. The dynamic deformation density maps, which show similar features, as well as static deformation density maps for the second molecule of $\mathbf{1}$, are deposited as a Supplementary material.

For analysis of the bonds and interactions, we have applied the AIM approach [25]. The bond critical points (BCPs) for carbon-carbon bonds are mainly placed halfway between the atoms involved, with highest values of electron density found at the $\mathrm{BCP}$ of $\mathrm{C} 3-\mathrm{C} 4$ bond (pyridine ring), equal to $2.37 \mathrm{e} \AA^{-3}$ in 1, and $2.39 \mathrm{e} \AA^{-3}$ in 2 (Fig. 3). The greatest shift of BCP for $\mathrm{C}-\mathrm{C}$ bonds has been found for $\mathrm{C} 6-\mathrm{C} 7(0.12 \AA / 0.10 \AA$ towards C7), maybe due to the definitely different character of both carbon atoms. It might be noted, that the distribution of carbon-carbon BCP's in $\mathbf{2}$ is apparently less symmetrical: seven out of ten BCP's are located significantly far from the
Fig. 6 Graphical representation of atomic charges calculated from $N_{\text {val }}-P_{\text {val }}$ or integrated atomic charges over the atomic basins (AIM)
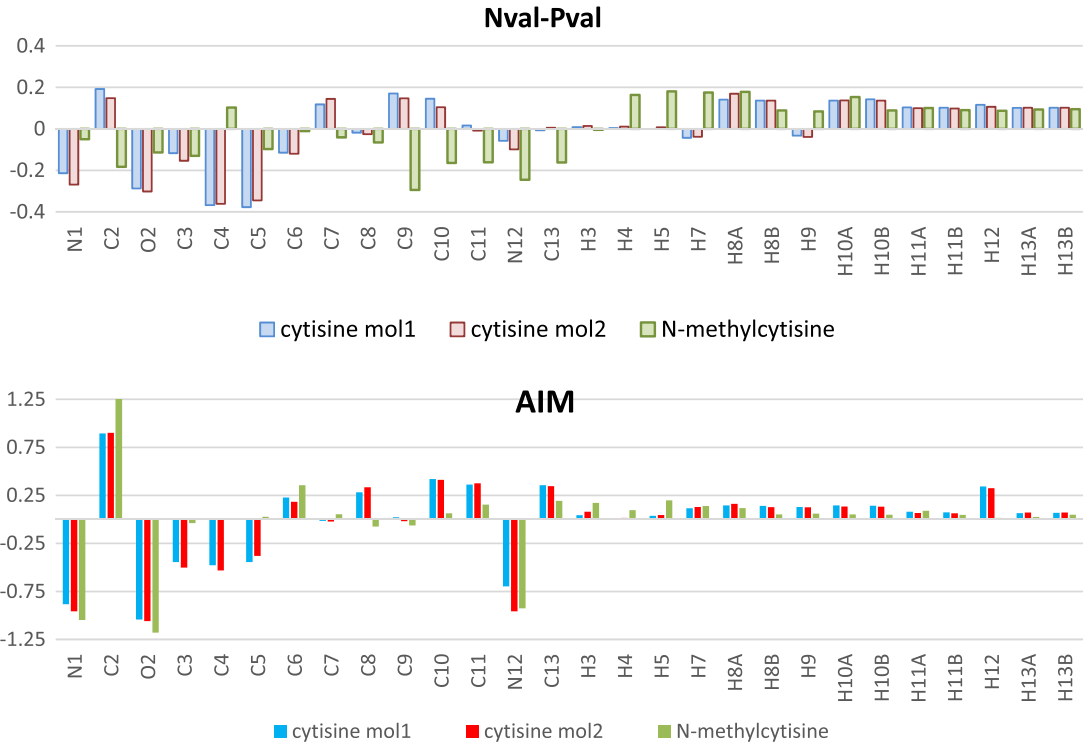
Table 2 Distances and topological characteristics of the BCPs in $\mathbf{1}$

\begin{tabular}{lllllllllll}
\hline Atom1 & Atom2 & D12 & D1cp & D2cp & $\rho_{\text {bcp }}$ & $\nabla^{2}$ & $\lambda_{1}$ & $\lambda_{2}$ & $\lambda_{3}$ & TYPE \\
\hline $\mathrm{H} 32$ & $\mathrm{O} 2$ & 2.1296 & 0.8024 & 1.3278 & 0.0912 & 1.74 & -0.36 & -0.35 & 2.46 & $\mathrm{NH} \cdots \mathrm{O}$ \\
$\mathrm{H} 12$ & $\mathrm{O} 22^{\mathrm{i}}$ & 2.3209 & 0.9481 & 1.3879 & 0.068 & 1.13 & -0.25 & -0.25 & 1.63 & $\mathrm{NH} \cdots \mathrm{O}$ \\
$\mathrm{H} 24$ & $\mathrm{O}^{\mathrm{ii}}$ & 2.4062 & 1.0004 & 1.4129 & 0.066 & 1.00 & -0.23 & -0.22 & 1.45 & $\mathrm{CH} \cdots \mathrm{O}$ \\
$\mathrm{H} 33 \mathrm{~B}$ & $\mathrm{O}^{2} 2^{\mathrm{iii}}$ & 2.4232 & 1.0138 & 1.422 & 0.0614 & 0.99 & -0.22 & -0.22 & 1.43 & $\mathrm{CH} \cdots \mathrm{O}$ \\
$\mathrm{H} 4$ & $\mathrm{~N}^{2} 2^{\mathrm{iii}}$ & 2.5289 & 1.028 & 1.5127 & 0.0576 & 0.82 & -0.14 & -0.14 & 1.09 & $\mathrm{CH} \cdots \mathrm{N}$ \\
$\mathrm{H} 11 \mathrm{~B}$ & $\mathrm{C}^{\mathrm{iv}}$ & 2.631 & 1.0738 & 1.5674 & 0.0531 & 0.68 & -0.14 & -0.11 & 0.93 & $\mathrm{CH} \cdots \mathrm{C}$ \\
$\mathrm{H} 25$ & $\mathrm{O} 22^{\mathrm{iii}}$ & 2.555 & 1.0998 & 1.4676 & 0.0472 & 0.71 & -0.15 & -0.14 & 1 & $\mathrm{CH} \cdots \mathrm{O}$ \\
\hline
\end{tabular}

D12: distance between two atoms; D1cp, D2cp: distance from the first and the second atom to the critical point, Laplacian $\left[\nabla^{2}\left(\rho_{\mathrm{bcp}}\right)\left(\mathrm{e} \AA^{-5}\right)\right]$ electron density $\left[\rho_{\mathrm{bcp}}\left(\mathrm{e} \AA^{-3}\right)\right]$ and mean curvature of the Hessian matrix $\lambda_{1}, \lambda_{2}, \lambda_{3}$ Symmetry codes: ${ }^{\mathrm{i}} 2-\mathrm{x},-1 / 2+\mathrm{y}, 1 / 2-\mathrm{z} ;{ }^{\mathrm{ii}} \mathrm{x}, 1+\mathrm{y}, \mathrm{z} ;{ }^{\mathrm{iii}}-1+\mathrm{x}, \mathrm{y}, \mathrm{z} ;{ }^{\text {iv }} 1-\mathrm{x},-1 / 2+\mathrm{y}, 1 / 2-\mathrm{z}$ respective middlepoints of the bonds (in 1 there is only one such example). Carbon-nitrogen and carbon-oxygen BCPs in both structures are-obviously due to the differences in charges - shifted towards the carbon atoms. The $\mathrm{C}=\mathrm{O}$ bonds have overall largest values of electron density at the BCP: $3.00 / 2.98$ e $\AA^{-3}$ in two molecules of $1,2.94 \mathrm{e} \AA^{-3}$ in 2. Full characteristics of bond critical points can be found in the Supplementary material (Table 1).

The analysis of the basic features, like Laplacian, electron density at the bond critical point, and positive curvature of the Hessian matrix $\lambda_{3}$ (Fig. 4) shows that the significant differences between $\mathbf{1}$ and $\mathbf{2}$ are observed in the C and B rings, certainly due to the structural differences: absence/presence of the methyl substituent at N12 (Fig. 4).

The electrostatic potential plots of (1) and (2) are presented in Fig. 5. In case of $\mathbf{1}$, the negative potential is located in pyridine ring in both symmetry independent molecules, but the values differ quite significantly, probably as a result of the different interactions in which both molecules are involved. In 2 the values of potential within the molecule are generally smaller than in case of cytisine, the negative potential is observed only around oxygen atom and nitrogen $\mathrm{N} 12$ atom (from piperidine ring). Consequently, the dipole moments calculated for cytisine are significantly larger than for $\mathrm{N}$-methylcytisinie (36.52 D/5.67 D).

The comparison of atomic charges is not quite straightforward; however, it might be noted that the differences are generally due to the different definitions which can be used, consequently significant discrepancies in values and even in signs that can have been observed [26]. Using consequently, the same definition may allow for the-at least qualitative-comparison of the results. So, to analyze the differences in atomic charges we have compared the results for $N_{\mathrm{val}}-P_{\mathrm{val}}$ differences between the formal and refined population of valence electrons and-on the other hand-the integrated AIM charges [27]. The graphical representation of the values is shown in Fig. 6, all values are collected in Supplementary material, Table. Significantly more coherent results were obtained when calculating atomic charges integrated over the atomic basins (AIM approach). In case of $N_{\mathrm{val}}-P_{\mathrm{val}}$ the differences are much larger. This agrees generally with previous observations (for instance, [26]).

\section{Intermolecular interactions}

Bond critical points $(3,-1)$ have been found for 33 intermolecular contacts in the crystal structure of cytisine (30 of them have electron density at the critical point larger than $0.02 \mathrm{e} \AA^{-3}$ ), while in the structure of N-methylcytisine there are 20 such contacts with 16 with electron density at the $\mathrm{CP}$ above 0.02 e $\AA^{-3}$. The data for all these CPs are deposited as the Supplementary materials (Tables 3 and 4). Few shortest, and the most important interactions are listed in Tables 2 and 3 below.

As has been mentioned before, in course of the discussion of intramolecular BCPs, two independent molecules of $\mathbf{1}$ are involved in similar but not identical molecular interactions. For instance, oxygen atoms from both molecules accept different numbers of significant $\mathrm{N}-\mathrm{H} \cdots \mathrm{O}$ and $\mathrm{C}-\mathrm{H} \cdots \mathrm{O}$ hydrogen bonds, and the characteristics of formally similar interactions
Table 3 Distances and topological characteristics of the BCPs in 2 (definitions as in Table 2)

\begin{tabular}{lllllllllll}
\hline Atom1 & Atom2 & D12 & D1cp & D2cp & $\rho_{\text {bcp }}$ & $\nabla^{2}$ & $\lambda_{1}$ & $\lambda_{2}$ & $\lambda_{3}$ & Type \\
\hline $\mathrm{O} 2$ & $\mathrm{H}^{\mathrm{i}}$ & 2.4495 & 1.5137 & 0.9375 & 0.0452 & 0.80 & -0.13 & -0.10 & 1.03 & $\mathrm{CH} \cdots \mathrm{O}$ \\
$\mathrm{H} 7$ & $\mathrm{H}^{\mathrm{N} 0 \mathrm{~B}^{\mathrm{ii}}}$ & 1.9922 & 0.9698 & 1.0527 & 0.0497 & 0.72 & -0.16 & -0.14 & 1.02 & $\mathrm{H} \cdots \mathrm{H}$ \\
$\mathrm{O} 2$ & $\mathrm{H}^{\mathrm{i} 0 \mathrm{~B}^{\mathrm{iii}}}$ & 2.6744 & 1.4902 & 1.1997 & 0.046 & 0.69 & -0.17 & -0.13 & 0.99 & $\mathrm{CH} \cdots \mathrm{O}$ \\
\hline
\end{tabular}

Symmetry codes: ${ }^{\mathrm{i}} 3 / 2-\mathrm{x}, 1-\mathrm{y}, 1 / 2+\mathrm{z} ;{ }^{\mathrm{ii}} 1-\mathrm{x}, 1 / 2+\mathrm{y}, 1 / 2-\mathrm{z}$; ${ }^{\mathrm{iii}} 1 / 2+\mathrm{x}, 1 / 2-\mathrm{y}, 1-\mathrm{z}$ 


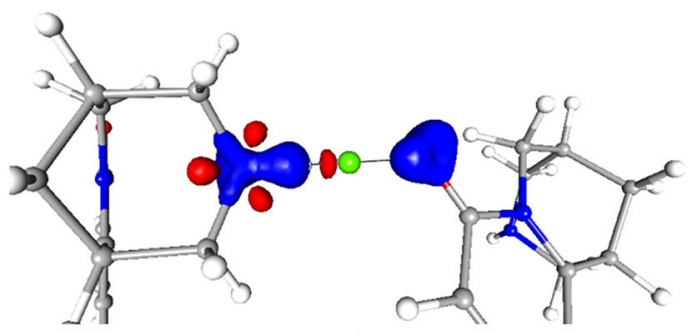

a)

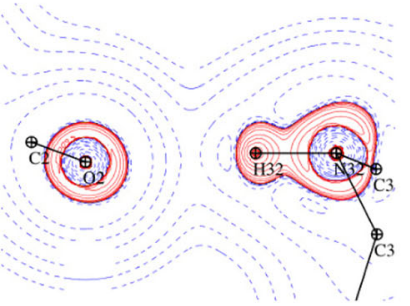

c)

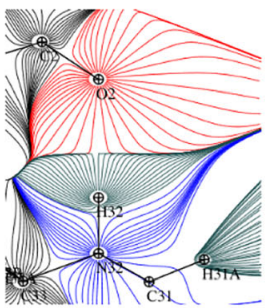

d)

Fig. 7 The 3D view of static defamation charge density map in the area

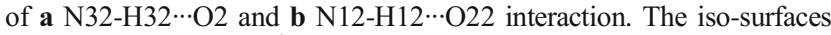
are drawn at $0.125 \mathrm{e} \AA^{-3}$. Positive and negative values are represented in blue and red, respectively. Representation of $\mathbf{c} \mathrm{N} 32-\mathrm{H} 32 \cdots \mathrm{O} 2$ and $\mathbf{e} \mathrm{N} 12-$

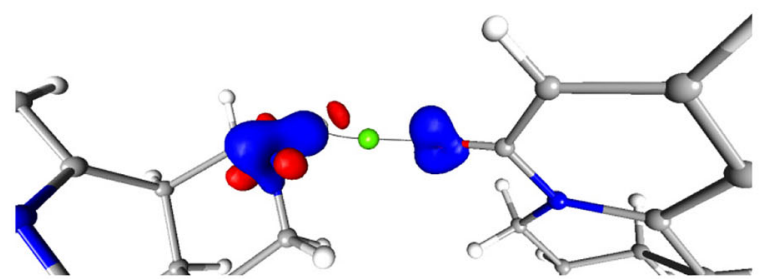

b)

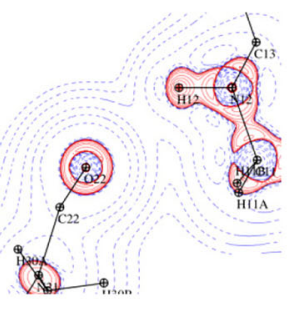

e)

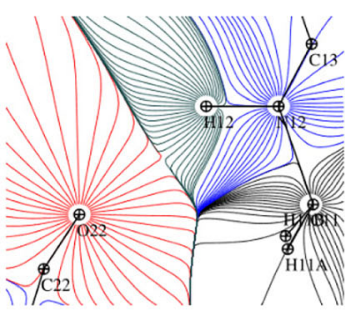

f)
$\mathrm{H} 12 \cdots \mathrm{O} 22$ in Laplacian maps, logarithmic contours in e $\AA^{-5}$. Red and blue contours denote positive and negative values, respectively. Representation of $\mathbf{d} \mathrm{N} 32-\mathrm{H} 32 \cdots \mathrm{O} 2$ and $\mathbf{f} \mathrm{N} 12-\mathrm{H} 12 \cdots \mathrm{O} 22$ gradient lines of the total electron density

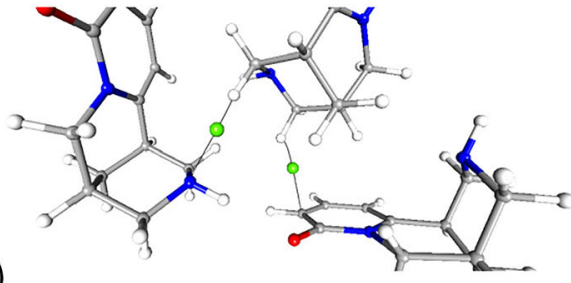

a)

Fig. $8 \mathrm{C}-\mathrm{H} \cdots \mathrm{N}$ and $\mathrm{C}-\mathrm{H} \cdots \mathrm{C}$ interaction: a bond path and associated critical point $\mathbf{b} 3 \mathrm{D}$ view of static deformation charge density map in the area of C-H$\mathrm{N}$ and C-H-C contacts. The iso-surfaces are drawn at 0.125 e $\AA .{ }^{3}$ Positive and negative values are represented in blue and red, respectively
Fig. $9 \mathrm{H} \cdots \mathrm{H}$ interaction: a bond path and associated critical point b 3D view of static defamation charge density map in the area of $\mathrm{H} \cdots \mathrm{H}$ contact. The iso-surfaces are drawn at $0.125 \mathrm{e} / \AA^{3}$. Positive and negative values are represented in blue and red, respectively

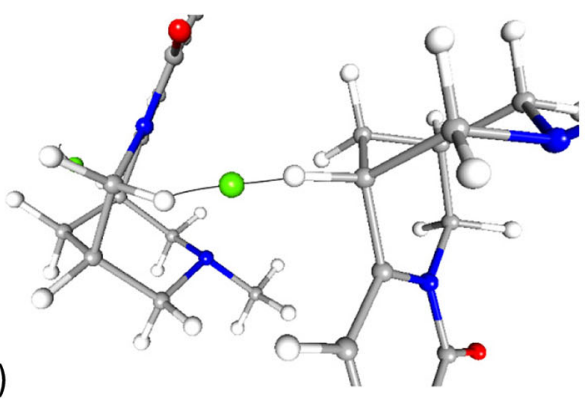

b)

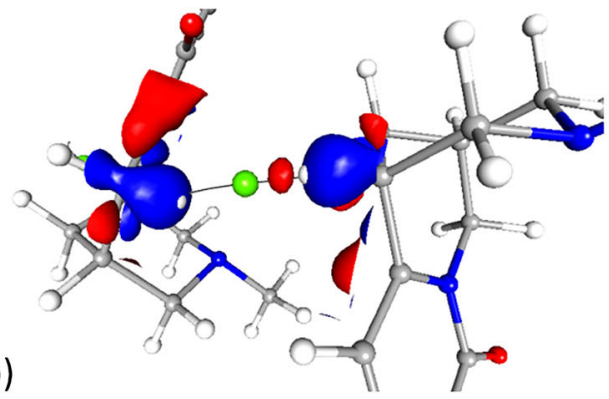




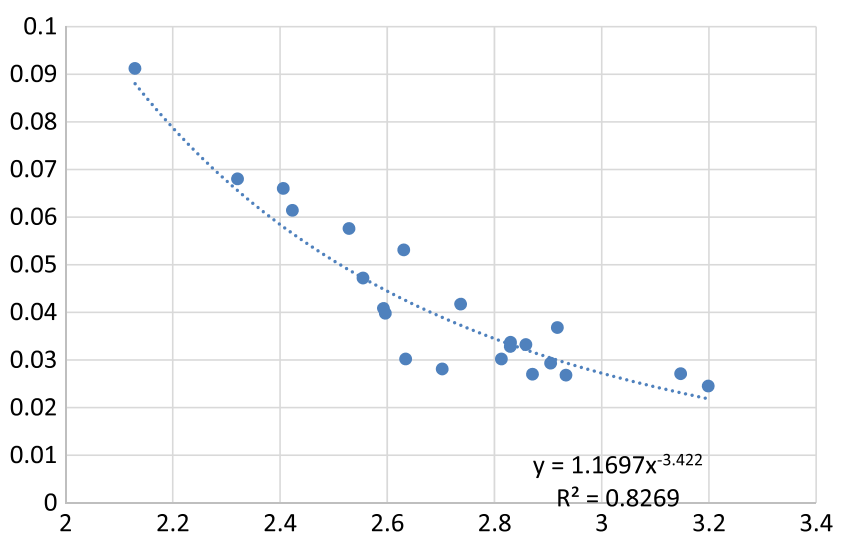

Fig. 10 A plot of $\rho(\mathrm{CP})$ vs. $R_{\mathrm{ij}}$ for intermolecular BCPs in $\mathbf{1}$ after removing $\mathrm{H} \cdots \mathrm{H}$ interactions

are also quite different. For instance, the most important N$\mathrm{H} \cdots \mathrm{O}$ hydrogen bond is much stronger for this accepted by molecules A than for that accepted by B.

This difference can be related to the less directional geom-

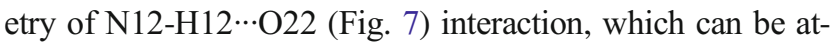
tributed to the fact that $\mathrm{O} 22$ atom is acceptor of more $\mathrm{CH} \cdots \mathrm{O}$ contacts than $\mathrm{O} 2$.

Among the most important interactions, besides $\mathrm{CH} \cdots \mathrm{O}$ hydrogen bonds, also $\mathrm{C}-\mathrm{H} \cdots \mathrm{N}$ and $\mathrm{C}-\mathrm{H} \cdots \mathrm{C}$ contacts have been found (Fig. 8). The first one might be an interaction between the hydrogen atom from aromatic ring and the lone pair of piperidine nitrogen atom. The second one is less directional, and-although critical point has been found between hydrogen and carbon atom from aromatic ring - it cannot be classified as $\mathrm{C}-\mathrm{H} \cdots \pi$ interaction with the double $\mathrm{C} 3=\mathrm{C} 4$ bond electrons. It is consistent with the abovementioned fact, that $\mathrm{C} 3$ and $\mathrm{C} 4$ atoms are the area of the most negative potential in the whole molecule, so this interaction can have attractive nature, which can be seen in Fig. 8.

Due to the methylation of atom N12, the molecule 2 lacks strong hydrogen bond donors, and therefore in its structure all intermolecular interactions are much weaker than in case of $\mathbf{1}$ (Table 3).

One of the strongest contacts is of $\mathrm{H} \cdots \mathrm{H}$ type (Fig. 9), with the highest value of electron density at the critical point $\left(0.050 \mathrm{e} / \AA^{3}\right)$. Such $\mathrm{H}^{\cdots} \cdots \mathrm{H}$ bonding between two similar hydrogen atoms (both connected to carbon atoms) has almost all characteristics of its critical point similar to other weak hydrogen bonds, which can prove the importance of such type of interactions. The presence of $\mathrm{H} \cdots \mathrm{H}$ bonding has been postulated in other studies (for instance, [28]). It can be noted that in case of $\mathrm{N}$-methylcytisine the strongest $\mathrm{H} \cdots \mathrm{H}$ interactions are found between slightly different types of hydrogen atoms (for instance one from the aromatic ring, and the other from the methylene group), and in such cases the critical point is shifted towards the atom with higher positive charge (as defined by the integration over the appropriate atomic basin).

Figure 10 shows the plot of the chosen characteristics of the intermolecular BCPs vs. $R_{\mathrm{ij}}$ distance. This plot, after removing the debatable $\mathrm{H} \cdots \mathrm{H}$ interactions, fits quite well into exp.-type dependence, as postulated, e.g., by Wozniak et al. [29, 30].

\section{Conclusions}

The experimental charge density studies as well as topological analysis have been performed for two bioactive molecules: cytisine and its N-methyl derivative. The analyzed features show that besides the structural similarities of both alkaloids, the electron density distribution and consequently all its derivatives differ quite significantly, which can be (except the steric factors) the reason of definitely lesser activity of (2) towards $\alpha 4 \beta 2$ receptor.

Acknowledgements This research was carried out as a part of a National Science Center project (Grant No. 2013/11/B/ST5/01681).

Open Access This article is distributed under the terms of the Creative Commons Attribution 4.0 International License (http:// creativecommons.org/licenses/by/4.0/), which permits unrestricted use, distribution, and reproduction in any medium, provided you give appropriate credit to the original author(s) and the source, provide a link to the Creative Commons license, and indicate if changes were made.

\section{References}

1. Rouden J, Lasne M, Blanchet J, Baudoux J (2014) (-)-Cytisine and derivatives: synthesis, reactivity, and applications. Chem Rev 114: $712-778$

2. Tutka P, Zatoński W (2006) Cytisine for the treatment of nicotine addiction: from a molecule to therapeutic efficacy. Pharmacol Rep 58:777-798

3. Fagerström K, Balfour DJ (2006) Neuropharmacology and potential efficacy of new treatments for tobacco dependence. Expert Opin Investig Drugs 15:107-116

4. Seeger R (1992) Cytisine as an aid for smoking cessation (in German). Med Monatsschr Pharm 15:20-21

5. Boido C, Tasso B, Boido V, Sparatore V (2003) Cytisine derivatives as ligands for neuronal nicotine receptors and with various pharmacological activities. Farmaco 58:265-277

6. Carbonnelle E, Sparatore F, Canu-Boido C, Salvagno C, BaldaniGuerra B, Terstappen G, Zwart R, Vijverberg H, Clementi F, Gotti C (2003) Nitrogen substitution modifies the activity of cytisine on neuronal nicotinic receptor subtype. Eur J Pharmacol 471:85-96

7. Barlow RB, McLeod LJ (1969) Some studies on cytisine and its methylated derivatives. Br J Pharmacol 35:161-174

8. Barlow RB, Johnson O (1989) Relations between structure and nicotine-like activity: X-ray crystal structure analysis of (-)-cytisine and $(-)$-lobeline hydrochloride and a comparison with $(-)$-nicotine and other nicotine-like compounds. Br J Pharmacol 98:799-808

9. Pérez EG, Méndez-Gálvez C, Cassels BK (2012) Cytisine: a natural product lead for the development of drugs acting at nicotinic acetylcholine receptors. Nat Prod Rep 29:555-567 
10. Coe JW, Brooks PR, Vetelino MG, Wirtz MC, Arnold EP, Huang J, Sands SB, Davis TI, Lebel LA, Fox CB, Shrikhande A, Heym JH, Schaeffer E, Rollema H, Lu Y, Mansbach RS, Chambers LK, Rovetti CC, Schulz DW, Tingley III FD, O’Neill BT (2005) Varenicline: an $\alpha 4 \beta 2$ nicotinic receptor partial agonist for smoking cessation. J Med Chem 48:3474-3477

11. Fratiglioni L, Wang HX (2000) Smoking and Parkinson's and Alzheimer's disease: review of the epidemiological studies. Behav Brain Res 113:117-120

12. Rucktooa P, Haseler CA, Elk R, Smit AB, Gallagher T, Sixima TK (2012) Structural characterization of binding mode of smoking cessation drugs to nicotinic acetylcholine receptors through study of ligand complexes with acetylcholine-binding protein. J Biol Chem 287:23283-23293

13. Blessing RH (1989) DREADD-data reduction and error analysis for single-crystal diffractometer data. J Appl Crystallogr 22:396397

14. Farrugia LJ (2012) WinGX and ORTEP for Windows: an update. J Appl Crystallogr 45:849-854

15. Dolomanov OV, Bourhis LJ, Gildea RJ, Howard JAK, Puschmann H (2009) OLEX2: a complete structure solution, refinement and analysis program. J Appl Crystallogr 42:339-341

16. Sheldrick GM (2015) SHELXT-integrated space-group and crystal-structure determination. Acta Cryst A71:3-8

17. Zarychta B, Pichon-Pesme V, Guillot B, Lecomte C, Jelsch C (2007) On the application of an experimental multipolar pseudoatom library for accurate refinement of small-molecule and protein crystal structures. Acta Cryst A63:108-125

18. Hansen NK, Coppens $P$ (1978) Testing aspherical atom refinements on small-molecule data sets. Acta Cryst A34:909-921

19. Clementi E, Roetti C (1974) Roothaan-Hartree-Fock atomic wavefunctions: basis functions and their coefficients for ground and certain excited states of neutral and ionized atoms, $\mathrm{Z} \leq 54$. At Data Nucl Data Tables 14:177-478

20. Hirshfeld FL (1976) Can X-ray data distinguish bonding effects from vibrational smearing? Acta Cryst A32:239-244

21. Madsen AO (2006) SHADE web server for estimation of hydrogen anisotropic displacement parameters. J Appl Crystallogr 39:757-758

22. Meindl K, Henn J (2008) Foundations of residual-density analysis. Acta Cryst A64:404-418

23. Freer AA, Robins DJ, Sheldrake GN (1987) Structures of (-)cytisine and (-)- $N$-methylcytisine: tricyclic quinolizidine alkaloids. Acta Cryst C43:1119-1122

24. Mascagni P, Christodoulou M, Gibbons WA, Asres K, Phillipson JD, Niccolai N, Mangani S (1987) Solution and crystal structure of cytisine, a quinolizidine alkaloid. J Chem Soc Perkin Trans 2:1159-1165

25. Bader RFW (1994) Atoms in molecules: a quantum theory. Oxford University Press, Oxford

26. Koritsanszky T, Coppens $P$ (2001) Chemical applications of X-ray charge-density analysis. Chem Rev 101:1583-1627

27. Stash A, Tsirelson V (2002) WinXPRO: a program for calculating crystal and molecular properties using multipole parameters of the electron density. J Appl Crystallogr 35:371-337

28. Matta CF, Hernández-Trujillo J, Tang TH, Bader RFW (2003) Hydrogen-hydrogen bonding: a stabilizing interaction in molecules and crystals. Chem Eur J 9:1940-1951

29. Mallinson PR, Smith GT, Wilson CC, Grech E, Wozniak K (2003) From weak interactions to covalent bonds: a continuum in the complexes of 1,8-bis(dimethylamino)naphthalene. J Am Chem Soc 125:4259-4270

30. Dominiak PM, Makal A, Mallinson PR, Trzcinska K, Eilmes J, Grech E, Chruszcz M, Minor W, Wozniak K (2006) Continua of interactions between pairs of atoms in molecular crystals. Chem Eur J 12:1941-1949 